\title{
Training Room Management of Medical Conditions: Infectious Diseases
}

\author{
Robert G. Hosey, MD*, Richard E. Rodenberg, MD \\ Department of Family and Community Medicine, Department of Orthopaedics, \\ University of Kentucky Chandler Medical Center, 740 S. Limestone, Lexington, KY 40536, USA
}

\begin{abstract}
nfectious diseases in athletes account for a large percentage of encounters with the team physicians, as they do for outpatient physician visits in the general population. Fortunately, most of these illnesses are accompanied by only mildly irritating symptoms and are generally short-lived. Nevertheless, it seems that they occur at the most inopportune times for athletes, and can affect athletic participation and performance. In addition to compromising the activity of an individual athlete, the potential for inoculation of teammates and coaches is a real concern.

Viruses are far and away the leading causes of infectious disease. Other etiologic agents likely to be encountered in the training room include bacterial and fungal organisms. Less common illness such as tick-borne diseases and parasitic infections may also be seen. Because of the widespread prevalence of infectious diseases contracted by athletes of all ages, it is necessary for the sports medicine physician to be knowledgeable regarding diagnosis, treatment, and appropriate return to activity for this group of medical conditions.
\end{abstract}

\section{ATHLETES AND INFECTIOUS DISEASES}

A common misconception regarding athletes is that they rarely get sick because they are in "good shape." Using upper respiratory infections (URIs) as an example, we see that this is not necessarily the case. In reality, there seems to be a J-shaped curve describing the relationship between level of exercise and risk of URI, whereby individuals who are sedentary and those who perform excessive strenuous exercise are both at increased risk of infection [1,2]. Although the reason for this relationship is not completely understood, an impaired immune response appears to be a major contributing factor to susceptibility in athletes who perform excessive strenuous exercise.

Athletes, especially at the collegiate and professional level, are likely to be subjected to significant travel requirements, group meetings and meals, and residence in large housing quarters (ie, dormitories). These requirements are

Corresponding author. E-mail address: rhosey@email.uky.edu (R.G. Hosey). 
likely to increase risk of exposure to infectious agents. A study of illness incidence among collegiate athletes [3] found that $98 \%$ of the athletes experienced at least one illness during a 2-month period in the winter. The overwhelming majority of the illnesses were classified as URIs. Other evidence indicates that athletes tend to be risk takers, and may thereby increase their likelihood of contacting certain types of infectious disease, most notably sexually transmitted diseases (STDs) [4]. The relationship between exercise and relative risk of infectious disease remains debatable. What is clear is that athletes will experience the affects of common infectious diseases that may hinder participation, performance, and in some cases their long-term well-being.

\section{UPPER RESPIRATORY INFECTIONS}

Upper respiratory infections are likely to be the most common affliction treated in the training room setting. In the general population, one can expect to experience from one to six "colds" per year. This average probably holds true for athletes as well. In examining illness patterns among participants of the Olympic Games, URIs consistently predominate [5]. Although less welldocumented, viral URIs are commonplace among collegiate and scholastic athletes as well.

\section{Etiology}

Identification of the specific virus responsible for an acute upper respiratory illness is simply not feasible nor necessary. The most common classes of viruses causing the common cold include rhinoviruses and coronaviruses. There are greater than 100 serotypes of rhinoviruses alone, a characteristic that allows evasion of host immunity and ongoing susceptibility to URIs. Certain viruses are more prevalent at varying times of the year, whereas others are capable of producing more significant clinical symptoms. Table 1 lists some viral agents associated with URIs.

\section{Diagnosis and Treatment}

Diagnosis of URIs is clinical. Most symptomatic individuals have one or multiple complaints, including rhinorrhea, headache, fatigue, sore throat, cough, and congestion. These may be accompanied by a low-grade fever. Severity of

\section{Table 1}

Select viral agents associated with upper respiratory infections

\begin{tabular}{lll} 
Viral family & $\begin{array}{l}\text { Highest seasonal } \\
\text { prevalence }\end{array}$ & Additional information \\
\hline Rhinovirus & Fall/spring & $>100$ serotypes \\
Coronavirus & Winter & $\begin{array}{l}\text { Viral family causing SARS } \\
\text { Latent infection in lymphoid }\end{array}$ \\
Adenovirus & All seasons & $\begin{array}{l}\text { tissue possible } \\
\text { Coxsackie virus associated } \\
\text { with myocarditis }\end{array}$ \\
\hline
\end{tabular}

Abbreviation: SARS, severe acute respiratory syndrome. 
symptoms will often vary depending on host immunity and the responsible viral pathogen. Treatment involves symptomatic and supportive care. Overthe-counter (OTC) decongestants, antipyretics, and cough suppressants are usually helpful in controlling symptoms. Use of nasal sprays such as oxymetazoline work quickly to relieve nasal congestion, but should be limited to shortterm use $(<48-72$ hours) to prevent rebound symptoms.

\section{Participation Guidelines}

The decision to return an athlete who has a URI to training or competition should be made on a case-by-case basis, taking the situation, symptomatology, and individual athlete into consideration. In this process, the risks involved in returning to activity (worsening or prolongation of illness) and its affect on performance should be evaluated.

A well-known but rare complication of viral URIs is viral myocarditis. Coxsackie virus is perhaps the most common causative viral agent. Although there is no evidence to suggest that exercise during a viral infection increases the likelihood of myocarditis in humans, exertion does increase viral replication rates and severity of morbidity associated with myocarditis in murine models infected with Coxsackie virus [6]. Viral myocarditis has been associated with sudden cardiac death, and accounts for roughly 3\% to 5\% of known cases in young athletes [7]. The ability of common URI viruses to cause myocarditis and a potential lethal outcome remains a strong reminder of the risks of common viral infections; however, because any sudden death occurrence in a young athlete receives significant publicity, this association may be overvalued, and should not be the sole factor determining return to training activity.

Conflicting evidence exists regarding performance and physiologic markers in individuals who have URIs. Some studies $[8,9]$ show alterations in cardiac, skeletal muscle, and respiratory function in persons experiencing infectious URIs. Conversely, Weidner et al $[10,11]$ found no significant change in pulmonary function tests, $\mathrm{VO}_{2}$ maximum, or duration of cold symptoms during repeated submaximal exercise testing in symptomatic young adults infected with a strain of rhinovirus compared with controls. One distinguishing factor among these data may be the presence or absence of a fever. In Weidner's work, the participants did not have a fever. The finding of fever may signify a more severe infection. Febrile illness results in increased metabolism, caloric, and fluid requirements, and can decrease pulmonary perfusion, concentric muscle strength, and cognitive function [12]. As a result of sparse and conflicting data regarding athletic performance during acute viral URIs, the decision to allow athletic participation can be a difficult one. A regularly cited guideline that may be useful is the so called "neck check" [13]. In this scenario, if symptoms are limited to locations above the neck (nasal congestion, runny nose, sore throat, and the like), the athlete is allowed to perform a 10-minute test period of light exercise. If the athlete feels better or symptoms do not worsen, he or she may continue the workout at a subnormal intensity, with gradual return to full intensity training over subsequent days. If symptoms worsen during the test period, the training session should be ended. If symptoms below the neck or 
systemic symptoms are present (vomiting, diarrhea, fever, myalgias, lymphadenopathy, and so on) physical exertion should be delayed until these symptoms have resolved [13]. The use of this management approach may help somewhat to objectify return-to-activity decisions. It may also lessen the risk of the athlete developing complications such as viral myocarditis.

Attempts should be made to prevent illness whenever possible. With viral URIs it is important to limit exposure to viral pathogens. Toward this end, symptomatic athletes should be isolated, the importance of hand washing stressed to all personnel in the training room environment, and the sharing of personal items, including water bottles, should be avoided. Additionally, influenza immunizations should be considered for athletes who will be participating or training during the influenza season.

\section{PHARYNGITIS}

Pharyngitis can present as an isolated complaint or in association with numerous other symptoms. The majority of cases are caused by viruses, with numerous viral strains producing a sore throat as the main symptom. Included among these are Epstein-Barr virus (EBV), adenovirus, Herpes simplex, and Coxsackievirus A and B [14]. Post-nasal drainage may also present with a complaint of a sore throat as mucosal irritation of the posterior pharynx occurs. Often the irritation is worse in the morning and improves throughout the day.

Group A beta-hemolytic streptococci are the bacteria most closely associated with causing bacterial exudative pharyngitis, or "strep throat." Although more common in preteens and adolescents, strep throat can be encountered in adults as well. Symptoms may consist of headache, nausea, malaise, fever and chills, odynophagia, and sore throat. Clinical findings may reveal exudative pharyngitis, anterior cervical lymphadenitis, and palatal petechiae. Both rapid assays (strep screen) and throat cultures are available to help confirm a diagnosis. These tests, however, have sensitivities approaching $90 \%$ or more for cultures and between $80 \%$ to $90 \%$ for rapid antigen screens at best [15]. Thus, false negatives are a distinct possibility. Additionally, these tests fall under clinical laboratory improvement amendments (CLIA) regulations and are therefore impractical for use in a training room setting.

Symptomatic treatment of viral pharyngitis is recommended, whereas antibiotics are recommended for streptococcal pharyngitis. The goal of antibiotic therapy in cases of strep throat is the prevention of potential complications, including sinusitis, peri-tonsillar abscess formation, otitis media, and mastoiditis. A full course of antibiotics (10 days of penicillin or equivalent) also helps reduce the risk of nonsuppurative complications, mainly rheumatic fever. Analgesics, salt-water gargles, and antipyretics such as acetaminophen can help alleviate much of the discomfort associated with acute pharyngitis.

\section{SINUSITIS}

Acute rhinosinusitis is one of the most common problems encountered in primary care. It involves inflammation of both the nasal and para-nasal sinus 
mucosa. Symptoms and viral etiology are similar to those experienced with URIs. Viruses are responsible for the overwhelming majority of cases, with only about one in eight individuals presenting with URI symptoms having a bacterial etiology [16]. Bacterial infection should be suspected in patients who have purulent nasal discharge, facial or tooth pain, unilateral sinus tenderness, or symptoms that worsen after initial improvement [17]. Symptoms that last for longer than 10 days also increase the likelihood of a bacterial infection. In these cases, up to $60 \%$ of sinus aspiration cultures are positive for a bacterial pathogen [18]. Streptococcus pneumoniae and Hemophilus influenzae are the two most common causes of bacterial rhinosinusitis in the community setting, accounting for up to 70\% of cases [19]. Antibiotic treatment regimens are recommended to be reserved for those individuals who have URI symptoms lasting greater than 10 to 14 days, or whose symptoms worsen after 5 to 7 days [20]. These recommendations are designed to help limit the inappropriate use of antibiotics and prevent the formation of antibiotic-resistant bacteria. Amoxicillin or trimethoprim-sulfamethoxazole are appropriate firstline therapies.

Several conditions are cited as predisposing factors in the development of bacterial rhinosinusitis. Some of these include variations in nasopharyngeal anatomy, cigarette smoking, allergic rhinitis, diabetes, use of topical nasal medications, and presence of immune deficiency. Risk factors directly related to sports activity are less well-defined. There are anecdotal reports of higher incidence of sinus infections in swimmers, and even a term applied to this malady, so-called "swimmer's sinusitis." Leading theories as to etiology of swimmer's sinusitis include the introduction of water into the nasal cavity and sinuses, and cooling of the skin and nasal mucosa during swimming. Scientific support for either theory is sparse. In a single study comparing 20 swimmers and controls, Deitmer and Scheffler [21] found that swimmers report more nasal congestion symptoms and more episodes of sinusitis compared with controls. Ear, nose, and throat (ENT) examination of the same individuals revealed swimmers to have a higher incidence of irritated nasal mucosa and swollen adenoids, but no significant change in function of nasal mucosa. As a result, the authors postulated that cooling of the skin during water immersion may lead to alterations in nasal blood flow and swelling of the nasal mucosa, and ultimately to increased risk of sinusitis [21].

\section{OTITITIS MEDIA/EXTERNA}

Ear infections can occur in the middle ear (otitis media), external auditory canal (otitis externa) or both. Over 20 million cases of otitis media (OM) are diagnosed annually in the United States alone. Although these infections are predominately seen in the pediatric population, adult cases occur as well. Eustachian tube dysfunction/obstruction resulting in negative inner ear pressure and fluid formation provide the setting for development of OM. Viral pathogens account for approximately $30 \%$ of cases of OM. The most common bacterial causes include $S$ pneumoniae, Hinfluenzae, and Moraxella catarrhalis. Symptoms of ear fullness 
or pain, decreased hearing ability, and subjective fever are often present. Otoscopic examination typically reveals a dull, erythematous, nonmobile (with pneumatic otoscopy) tympanic membrane (TM). The TM may sometimes be bulging, and purulent fluid may be visualized in the middle ear. The treatment of $\mathrm{OM}$ with oral antibiotics is generally indicated. Analgesics such as acetaminophen or nonsteroidal anti-inflammatory drugs (NSAIDs) can be used to reduce patient discomfort.

Otitis externa $(\mathrm{OE})$ is an infection involving the external auditory canal. $\mathrm{OE}$ occurs when bacterial or fungal organisms are allowed to proliferate in the epithelium of the canal. This often results after a superficial abrasion compromises the integrity of the epidermis, allowing for penetration by pathogens. Pseudomonas aeruginosa is the most identifiable causative agent of OE. Fungal organisms such as Aspergillus have also been identified [22]. Acute $\mathrm{OE}$ is characterized by otalgia, reduced hearing, and aural drainage. Examination is likely to reveal foul-smelling discharge, erythema and edema of the auditory canal, and tragal tenderness. Enlarged preauricular, postauricular, or cervical lymph nodes may also be appreciated. Treatment involves cleansing of the auditory canal and use of topical medications. Cleaning of debris from the canal by irrigation allows for maximum effectiveness of aural preparations. Combination antibiotic/corticosteroid drops (eg, polymyxin $\mathrm{B} / \mathrm{hydrocortisone}$ ) are usually effective. An acidifying/corticosteroid agent $(2 \%$ acetic acid/hydrocortisone) can be used as an alternative for mild infections. Antifungal medications should be added in cases in which otomycosis is suspected. Use of an ear wick may be needed with each of these treatments to help retain the medications within the auditory canal.

In athletes experiencing $\mathrm{OM}$, air travel restrictions may be necessary, owing to pressure changes that occur with ascending and descending from altitude. In this situation, severe pain and TM rupture may occur with rapid changes in atmospheric pressure. Similar fluctuations in pressure can occur underwater, with depths as shallow as 4 feet causing injury to the TM [23]. Therefore, air travel and underwater activity are not advised until resolution of the infection.

Several conditions predispose the athlete to the development of OE. Repetitive water exposure, pre-existing allergic conditions, and excessive or inadequate cerumen have been implicated as risk factors for OE [23]. Swimmers and divers are consequently the athletes most likely to be affected. Recurrent water exposure in these athletes may lead to decreased amounts of cerumen, drying of the ear canal, and resultant itching. Digital manipulation and introduction of cleaning instruments into the canal to alleviate itching often results in abrasions of the epidermis, providing an opportunity for infection to occur [24]. Athletes who have OE should keep the ear dry by staying out of the water during treatment. This may be accomplished by using form-fitting ear plugs as well. Prevention measures include education efforts to eliminate the use of ear cleaning utensils and excessive efforts to remove protective cerumen. Combination drying/acidifying drops such as isopropyl alcohol and acetic acid can also be used as a prophylactic measure. 


\section{CONJUNCTIVITIS}

The term conjunctivitis is used to describe a variety of conditions that result in the inflammation of the conjunctiva. Etiology of conjunctivitis is commonly grouped into one of three categories: viral, bacterial, or allergic.

\section{Viral Conjunctivitis}

Adenovirus infection is the most common cause of viral conjunctivitis. It is highly contagious and may be spread by contact with contaminated objects and subsequent inoculation by rubbing of the eyes. Viral conjunctivitis usually involves a single eye initially, with spread to the other eye commonly in the following days. Examination of the eye classically reveals erythema and edema of the conjunctiva with associated watery discharge. A tender preauricular lymph node may also be present. Treatment consists of limiting contact with other individuals to prevent spread, and supportive care. Ocular vasoconstrictors and cool compresses may provide symptom relief. The use of corticosteroids should be left to the discretion of an ophthalmologist to prevent contributing to ocular damage from an infection with Herpes simplex virus, which can closely resemble that of adenovirus.

\section{Bacterial Conjunctivitis}

Leading organisms causing acute bacterial conjunctivitis include Staphylococcus aureus, $S$ pmeumoniae, and $H$ influenzae. Staph conjunctivitis is more likely to be encountered in adults, whereas $S$ pneumoniae and $H$ influenzae are more common in pediatric patients [25]. Similar to viral conjunctivitis, bilateral eye involvement is often preceded by unilateral symptoms. The presence of purulent discharge accompanied by conjunctival inflammation is the hallmark of bacterial conjunctivitis. Unfortunately, signs and symptoms are relatively poor prognosticators for differentiating among the different causes of conjunctivitis [26]. The use of empiric antibiotic therapy is therefore controversial. In general, most practitioners opt to treat suspected bacterial conjunctivitis with antibiotics. In this case, using an inexpensive broad-spectrum antibiotic is recommended. Ointments such as erythromycin or bacitracin-polymyxin B may be used in children. Ophthalmic solutions (trimethoprim-polymyxin B) are preferred for adults. Aminoglycosides provide an alternative class of antibiotic therapy and are good choices for suspected gram-negative pathogens. The use of cultures is indicated in refractory and severe cases of conjunctivitis.

\section{Allergic Conjunctivitis}

An IgE-mediated hypersensitivity reaction precipitated by exposure to allergens (dust, mold, pollen, animal dander, and the like) can result in allergic conjunctivitis. Symptoms typically include itching, redness, and watering of the eyes. Affected individuals may note a seasonal pattern to their symptoms, and may be more likely to experience other atopic conditions. In addition to removal of the offending allergen, treatment with topical antihistamines, levocabastine hydrochloride ophthalmic suspension (Livostin), NSAIDs (ketorolac tromethamine), and mast cell stabilizers (cromolyn sodium or lodoxamide) can be useful. 
Mast cell stabilizers, however, are not helpful for immediate relief of symptoms, because they work to prevent the release of histamine and usually require approximately 2 weeks of treatment before being effective [27]. Oral antihistamines may also prove beneficial in treatment of ocular and other symptoms associated with hay fever.

\section{Considerations in Athletes}

Chlorine exposure such as that encountered by swimmers and divers may precipitate a chemical conjunctivitis. Examination of the chlorine content of the pool water should be pursued in these situations. Athletes who have conjunctivitis and who wear contact lenses should be advised to discontinue use of contacts until conjunctivitis is resolved. Prescription glasses or sport goggles may be worn during this time period to provide protection to the eye and refractive correction.

\section{INFECTIOUS MONONUCLEOSIS}

Infectious mononucleosis (IM) is an acute medical condition caused by the EBV that classically presents as a triad of fever, tonsillar pharyngitis, and lymphadenopathy. EBV is a DNA herpes virus that enters the squamous epithelial cells and is transmitted person-to-person via oropharyngeal secretions, hence the term "kissing disease." More recent studies have shown that EBV has been found in the epithelial cells of the cervix and in semen, and can actually be transmitted by blood transfusion [28]. The prevalence of IM in the general population is 45 cases in every 100,000 people. In college students, however, $1 \%$ to $3 \%$ of the general student population acquires the disease each year, with rates of infection approaching 15\% in previously unexposed individuals [29].

The majority of EBV infections are subclinical and tend to affect various age groups differently. Fewer than 10\% of children develop clinical symptoms of IM, but adolescents and adults (ages 15-25) seem to develop symptoms 50\% to $70 \%$ of the time. The risk of developing symptomatic disease falls dramatically after the age of 35 , possibly due to prior exposure to the virus [30].

\section{Clinical Symptoms}

After exposure, EBV has an incubation period of 30 to 50 days. An intense T-cell mediated response triggers the onset of symptomatic disease. Initially, there is a 3 to 5 day prodromal period, with symptoms usually consisting of headache, malaise, and myalgias. In the acute phase (5-15 days) prominent fatigue, exudative pharyngitis, tonsillar enlargement, fever, and lymphadenopathy begin [31]. Splenomegaly results from lymphocytic infiltration of the spleen. The frequency of splenomegaly in IM has been estimated to range from $41 \%$ to $60 \%$, and can last longer than 21 days [32]. Jaundice and hepatomegaly may also occur but are less frequently encountered.

\section{Diagnosis}

There are several objective tests to accompany the clinical symptoms and solidify the diagnosis of IM. The white blood cell count is usually in the 12,000 to 
18,000 range, with $60 \%$ to $70 \%$ lymphocytes and $10 \%$ atypical lymphocytes on the peripheral smear. IM can also present with a relative neutropenia and thrombocytopenia. The mononucleosis sport (monospot) test, which is commonly used, tests for the presence of heterophile antibodies in the patient's serum. It is relatively specific, but varies in sensitivity, with false-negative rates approaching $25 \%$ during the first week of illness and falling to $5 \%$ by the third week [33]. Monospot tests are also unreliable in pediatric populations $(<10$ years of age), in whom it is likely to detect less than half of EBV infections. In instances where there is a strong clinical suspicion of IM and the monospot test is negative, EBV titers measuring viral capsid antigen (VCA), IgM, and IgG can help make a diagnosis.

\section{Potential Complications}

Several complications have been associated with IM, including Guillain-Barre syndrome, meningitis, neuritis, hemolytic-uremic syndrome, disseminated intravascular coagulation, and aplastic anemia. Splenic rupture, the most feared and potentially fatal complication of IM, occurs in approximately $0.1 \%$ to $0.2 \%$ of cases [34]. Obstruction from severe tonsilar enlargement can result in respiratory compromise and necessitate emergency action to establish an airway.

\section{Treatment}

The mainstay of treatment of IM is symptomatic and supportive care. Corticosteroids are indicated for treatment in those individuals who have severe hepatitis, myocarditis, and neurologic complications. Additionally, they may be recommended for those patients at risk of airway obstruction secondary to significant enlargement of tonsils and adenoids.

\section{Return-to-Play Considerations}

Deciding when it is safe for an athlete to return to athletic participation following acute IM is arguably one of the toughest decisions a team physician has to make. The complicated nature of this dilemma stems in part from the lack of scientific evidence available to give clear guidance.

Despite the small risk of splenic rupture, it has been observed in athletes who have IM [35]. Because the majority of IM cases result in some degree of splenomegaly, with a resultant increased risk of splenic rupture, athletes who have acute IM should not participate in sports. This recommendation includes noncontact physical activity as well, because splenic rupture is nearly as likely to occur without antecedent trauma $[34,36]$. Unfortunately, clinical examination is unreliable in determining the presence or absence of an enlarged spleen [37]. Diagnostic ultrasound can be performed in these situations to determine absolute spleen size, or even used serially to determine regression of splenomegaly [32]. This practice, however, is unlikely to be cost-effective, given the small risk of splenic rupture. Furthermore, there is a wide range of what constitutes normal spleen size among athletes [38]. Thus, without a baseline imaging examination, resolution of splenomegaly would be hard to determine even using serial ultrasounds. 
As a result, determining the appropriate time to return to activity can be difficult. Although delayed splenic rupture is possible, it is generally felt that the risk for splenic rupture with IM is greatest in the first 3 weeks of the illness [36]. Based on this observation, a period of recovery for at least 3 weeks following symptom onset has been proposed by some authors, whereas others suggest 5 to 6 weeks or longer may be more appropriate [39,40]. A 3-week recovery period (no physical activity) from time of symptom onset, followed by resumption of light activities in asymptomatic individuals (fourth week) and return to full participation (fifth week) is an algorithm that has been suggested in a recent preparticipation physical examination monograph [41]. Tailoring these guidelines to individual athletes in their specific situations will likely lead to the most appropriate medical management.

\section{MENINGITIS}

Meningitis is a potentially life-threatening medical emergency associated with multiple neurological complications and sequelae. A retrospective analysis looking at outcomes in adults treated with appropriate antibiotics for pneumococcal meningitis [42] revealed that only $47 \%$ of adults had a good outcome, and that $75 \%$ of patients had neurologic complications. Fortunately, the majority of reported meningitis cases in the literature concerning athletes are described as aseptic. Multiple case reports have described aseptic meningitis outbreaks among high school football players between 1978 and 1990 [43-48].

Aseptic meningitis refers to "Patients who have clinical and laboratory evidence for meningeal inflammation with negative routine bacterial cultures" [49]. The primary etiology of aseptic meningitis is the enteroviruses [50-52] (echovirus, Coxsackie A and B viruses, polioviruses, and the numbered enteroviruses) [52]. Enteroviruses are responsible for 55\% to 70\% of all aseptic meningitic cases and for $85 \%$ to $95 \%$ of cases for which a pathogen is ultimately identified [52]. Other viral causes include arboviruses, herpesviruses, zoster, adenovirus, HIV, lymphocytic choriomeningitis virus (LCM), measles, mumps, rubella, rabies, influenza $\mathrm{A}$ and $\mathrm{B}$, parainfluenza virus, parvovirus, and rotavirus. There are multiple nonviral etiologies, including fungal (blastomycosis, coccidomycosis, cryptococcus, histoplasmosis), bacterial etiologies (Mycoplasma, Borrelia burgdorferi, Brucella, Bartonella, Chlamydia, Mycobacterium tuberculosis [TB], Rickettsia species, Leptospira interogans, Listeria monocytogenes), protozoal etiologies, and noninfectious etiologies (medications, collagen vascular disease, malignancy, Reye's syndrome, adrenal leukodystrophy, vaccinations, poisoning, granulomatous disease, toxin exposure, trauma, Kawasaki disease, multiple sclerosis, and inborn errors of metabolism) $[51,52]$. The nonviral infectious etiologies are included because they are not easily detected by gram stain and are difficult to culture, often taking weeks to months to grow [52].

Aseptic meningitis is most prevalent during the summer and early fall months (ranging from July to December) [50,51]. Eneteroviruses are spread through the fecal oral route [50] (ie, shared infected water sources, in the form of containers, bottles, or ice cubes) [48]. Seasonal predilection and fecal oral route of spread 
may explain why aseptic meningitis is more prevalent in football and soccer athletes [48].

It is important to obtain a thorough history, including patient age, exposure to vectors (ticks or mosquitoes), medications taken recently, systemic illnesses, exposure to TB, travel out of the country, HIV risk factors, and history of meningitis or recent exposure to an individual who has meningitis [50]. This information is critical for determining possible etiologies and what type of empiric antibiotic to begin.

Aseptic meningitis is a commonly encountered disease process with a clinical presentation similar to that of bacterial meningitis [50]. These similarities can present a diagnostic dilemma. The presentation of meningitis can be acute (less than 24 hours) or subacute (occurring over 1 to 7 days) [50,51]. Obvious signs in the clinical presentation of meningitis include the classic triad of fever, headache, and neck stiffness (meningismus) [51,52]. This triad is often accompanied by other nonspecific symptoms, including nausea, vomiting, pharyngitis, diarrhea, photophobia, and focal neurologic signs. Symptoms can be accompanied by mental status changes ranging from lethargy to coma [50-52]. It is important to note that in a clinical series studying bacterial meningitis [51,53], only half of patients over the age of 16 presented with the classic triad. Clinical presentation may differ based on the age of the affected individual (neonate to elderly) [52]. Bacterial meningitis can have both a rapidly progressive and fulminant course, or an indolent course consisting of vague symptoms [51]. An indolent course is common when an individual has been pretreated with oral antibiotics [51].

Physical examination may reveal a febrile patient. There may be varying degrees of decline in mental status. Focal neurologic signs may be present which could be associated with a mass versus encephalitis. Papilledema raises concern for a space-occupying lesion versus increased intracranial pressure. Signs of meningeal irritation include meningismus (pain with passive flexion of the neck), Kernig's or Brudzinski's signs. Kernig's sign is positive if the examiner encounters resistance to passive extension of the knee while the hip is flexed. This may be done while the patient is supine or seated. Brudzinski's sign occurs when the supine patient has spontaneous flexion of the hips during attempted passive flexion of the neck. Rashes may be characteristic of the offending agent $[50,54]$.

Based on signs and symptoms and physical examination findings, it is virtually impossible to distinguish asceptic from septic bacterial causes of meningitis. Peripheral blood cell counts can either be normal or elevated [54]. Cerebrospinal fluid (CSF) analysis is the most important laboratory test for distinguishing aseptic from bacterial meningitis. The CSF fluid should be sent for cell count, protein, glucose, culture, and gram stain [50,51,54]. There is debate whether neuroimaging is needed before lumbar puncture (LP). There is a growing trend to image all patients before LP. Absolute guidelines for neuroimaging include impaired consciousness, deteriorating Glasgow Coma Score, signs of increased intracranial pressure (unstable blood pressure or 
heart rate, papilledema), and focal neurologic signs [51]. Age-appropriate, empiric, broad-spectrum antibiotics should not be delayed once blood cultures have been obtained if neuroimaging is to be performed [50-52]. More specific antibiotic coverage is added based on results of CSF Gram stain and culture and condition of the patient [50,51]. Initially, with viral meningitis or encephalitis, CSF samples usually demonstrate a pleocytosis. White cell counts can range from normal to several hundred cells per $\mathrm{mm}^{3}[51,52]$. Early in the course of the illness, the percentage of polymorphonuclear cells can predominate, but a shift to lymphocytic predominance occurs rapidly [51,52]. In bacterial meningitis, the white count is usually higher [50,51]. If the Gram stain does not reveal an etiology, and a monocytosis predominates, viral cultures should be attempted from the original specimen. Polymerase chain reaction (PCR) studies of the CSF can be sent for suspected viral or bacterial etiologies. PCR examination of CSF is especially valuable if herpes simplex virus or enteroviruses are suspected based on seasonal predilection or history [50-52] Increased red blood cells (RBCs) in the CSF are characteristic of Herpes simplex virus (HSV) infection [51]. CSF protein in aseptic meningitis is usually less elevated compared with bacterial meningitis [50,52]. CSF glucose should be compared with a simultaneous serum glucose. A CSF:serum glucose ratio of $66 \%$ is considered normal [50]. In aseptic meningitis, CSF glucose samples are usually within the normal range. Bacterial meningitis will cause a drop in CSF glucose $[50,52]$.

The specific therapies for etiologies of meningitis are better found in more extensive sources. Age-appropriate, broad-spectrum, empiric antibiotics are continued until bacterial etiologies have been ruled out [51,52]. Treatment for aseptic meningitis is usually supportive. The course is usually benign. Specific antiviral therapy with acyclovir is indicated for HSV meningitis with encephalitic symptoms [50-52,54]. For unusual nonviral etiologies of aseptic meningitis (ie, TB, spirochetal, rickettsial), specific treatment is indicated $[51,52]$. Otherwise, the cornerstone of treatment is hydration and antipyretics $[50-52,54]$.

Prevention revolves around good hand washing and decreasing use of shared water sources. Meningococcal vaccine immunization, with the quadrivalent vaccine, MPSV-4 (Menomume; serogroups A, C, Y, W-135), has been recommended by the United States Advisory Committee on Immunization practices (ACIP) for individuals more than 2 years old who have functional or surgical asplenia or who have terminal complement deficiencies, for those traveling or living in areas of the world where meningococcal infection is endemic, and for college age students (18-23 years olds) living in dormitories (threefold risk compared with age-matched controls) [55-57].

\section{GASTROENTERITIS}

Acute diarrhea is one of the most common medical problems in the world, ranking second only to acute URIs [57]. Thus, there is a distinct possibility that an athlete will be affected by this disorder. Agents causing acute gas- 
trointestinal illness can spread from person to person or can be acquired from food or environmental source (ie, pool or shared bottle water). Occasionally gastroenteritis can result from exposure to animals. Food and water can serve as the primary contagious source, or may have been contaminated by contact with infected people or animals [58]. Less common routes of fecal-oral exposure include aerosols, contaminated hands or surfaces, and sexual activity.

\section{Viral Gastroenteritis}

Pathogens responsible for the majority of gastroenteritis include viruses, bacteria, and protozoa. In industrialized nations, viruses cause the overwhelming number of gastrointestinal infections involving Caliciviruses (Norwalk-like virus), Rota viruses, Adenoviruses types 40 and 41, and Astroviruses. Norwalk virus outbreaks have been reported in contact sports such as football $[48,59,60]$. Common bacterial causes include Salmonella, Shigella, Campylobacter, E coli O157:H7, and Clostridium difficile. Protozoa including Giardia, Cryptosporidium, and Entamoeba histolytica are less common etiologies in industrialized areas. In underdeveloped nations Vibrio cholera, enteropathogenic E. Coli, protozoa, or intestinal parasites cause the majority of cases of acute gastrointestinal illness [58]. Inadvertent water exposures, usually involving ingestion of unchlorinated water, usually involve Giardia, Cryptosporidium, Salmonella, and Leptospirosis [59]. Any of the abovementioned agents could cause outbreaks in inadequately chlorinated swimming pools [59].

A concise review of features pertaining to the common pathogens and their presenting symptoms is presented in Table 2. Caliciviruses are by far the most common cause of viral gastroenteritis. Both Norwalk-like and Rotaviruses can cause outbreaks of infection by consumption of contaminated food or water; however, it is very important to recognize the very contagious nature of personto-person spread as well. Caliciviruses can be found not only in feces, but also in vomitus, and have been reported to spread by airborne droplets in nursing homes, hospitals, restaurants, and cruise ships. Both viruses survive well on environmental surfaces and are difficult to deactivate with ordinary cleaning agents (diluted bleach, 1:10 strength). Both require a small inoculum size. These factors make it difficult to control outbreaks in closed populations. Adenoviruses and Astroviruses are less well-studied, but are likely transmitted by person-to-person spread. Adenovirus may have a less contagious nature in adults [58]. Symptoms can include nausea and vomiting and large-volume watery stools (up to 10 or more per day) [61].

\section{Bacterial Gastroenteritis}

Bacterial agents can cause infection by three mechanisms: production of toxins, direct invasion of the bowel with resultant inflammation, and a combination of toxin production and invasion.

Salmonella are classified into three species: typhi, choleraesuis, and enteritidis. Most cases of salmonella infection in the United States are caused by enteritidis. Transmission occurs through ingestion of red meat, poultry, unpasteurized milk, and pork products that have been contaminated by animal feces [61]. 
Table 2

Common gastrointestinal pathogens

\begin{tabular}{|c|c|c|c|c|c|}
\hline Agent & Typical transmission & Likely symptoms & $\begin{array}{l}\text { Diagnosis } \\
\text { (stool studies) }\end{array}$ & Duration of symptoms & Outpatient treatment \\
\hline $\begin{array}{l}\text { Eschericia coli } \\
\text { EIEC }\end{array}$ & Contaminated food & $\begin{array}{l}\text { Fever, abdominal pain, low- } \\
\text { volume diarrhea }\end{array}$ & Stool culture & Varied & $\begin{array}{l}\text { Definite ATBXs based on } \\
\text { resistance patterns }\end{array}$ \\
\hline $\begin{array}{l}\text { Eschericia coli } \\
\text { EHEC }\end{array}$ & $\begin{array}{l}\text { Undercooked ground } \\
\text { beef, human contact }\end{array}$ & Diarrhea, HUS & Stool culture & $\begin{array}{l}\text { Symptoms begin after } \\
1-8 \text { days of incubation }\end{array}$ & $\begin{array}{l}\text { Supportive, ATBXs thought } \\
\text { to worsen disease course. }\end{array}$ \\
\hline $\begin{array}{l}\text { Salmonella } \\
\text { (nontyphoidal) }\end{array}$ & $\begin{array}{l}\text { Poultry, eggs, meat, } \\
\text { dairy }\end{array}$ & $\begin{array}{l}\text { Diarrhea (watery or bloody), } \\
\text { fever }\end{array}$ & Stool culture & $1-4$ days & $\begin{array}{l}\text { Treat only with ATBXs in } \\
\text { immunocompromised } \\
\text { and asplenia }\end{array}$ \\
\hline Shigella & $\begin{array}{l}\text { Human contact, } \\
\text { prepared food, } \\
\text { contaminated water }\end{array}$ & Diarrhea (watery or bloody), fever & Stool culture & $\begin{array}{l}\text { Varied; Some self- } \\
\text { resolve in } 7 \text { days, } \\
\text { others last weeks }\end{array}$ & $\begin{array}{l}\text { Definite ATBXs based on } \\
\text { resistance patterns }\end{array}$ \\
\hline
\end{tabular}




\begin{tabular}{|c|c|c|c|c|c|}
\hline Rotavirus & $\begin{array}{l}\text { Human contact, } \\
\text { contaminated food } \\
\text { and water }\end{array}$ & Fever, vomiting, diarrhea & $\begin{array}{l}\text { EIA, latex } \\
\text { agglutination }\end{array}$ & $\begin{array}{l}\text { Diarrhea } 3-8 \text { days; } \\
\text { Vomiting } 1-5 \text { days }\end{array}$ & Supportive only \\
\hline Astrovirus & Human contact & Diarrhea, vomiting & $\begin{array}{l}\text { EIA (not } \\
\text { commercially } \\
\text { available) }\end{array}$ & $1-14$ days & Supportive only \\
\hline $\begin{array}{l}\text { Adenovirus types } \\
40 \text { and } 41\end{array}$ & $\begin{array}{l}\text { Human contact (feces, } \\
\text { possibly vomitus) }\end{array}$ & Fever, vomiting, diarrhea & $\begin{array}{l}\text { EIA (not } \\
\text { commercially } \\
\text { available) }\end{array}$ & 1-7 days & Supportive only \\
\hline Cryptosproidium & $\begin{array}{l}\text { Tap water, human } \\
\text { contact }\end{array}$ & $\begin{array}{l}\text { Large-volume diarrhea, } \\
\text { abdominal pain, headache, } \\
\text { fever }\end{array}$ & $\begin{array}{l}\text { Microscopic } \\
\text { examination of } \\
\text { feces }\end{array}$ & $\begin{array}{l}\text { 5-6 days typically; } \\
\text { (range } 2-26 \text { days) }\end{array}$ & $\begin{array}{l}\text { In immunocompromised } \\
\text { cases, consider } \\
\text { antiparacystic/antibiotic } \\
\text { treatment }\end{array}$ \\
\hline $\begin{array}{l}\text { Entamoeba } \\
\text { histolytica }\end{array}$ & $\begin{array}{l}\text { Human contact (feces), } \\
\text { contaminated food or } \\
\text { water }\end{array}$ & Fever, bloody diarrhea & $\begin{array}{l}\text { Microscopic } \\
\text { examination of } \\
\text { feces }\end{array}$ & $\begin{array}{l}\text { Mild symptoms may be } \\
\text { present weeks to months }\end{array}$ & $\begin{array}{l}\text { Use both luminal } \\
\text { amebicide (for cysts) and } \\
\text { tissue amebicide } \\
\text { (for trophozoites) }\end{array}$ \\
\hline
\end{tabular}

Abbreviations: ATBX, antibiotics; EHEC, enterohemorrhagic; EIA, enzyme immunoassay; EIEC, enteroinvasive; ETEC, enterotoxigenic; HUS, hemolytic uremic syndrome.

Data from Adachi AA, Backer HD, DuPont HL. Infectious diarrhea from wilderness and foreign travel. In: Auerbach PS, editor. Wilderness medicine. 4th edition. St. Louis (MO): Mosby; 2001. p. 1237-70; and Musher DM, Musher BL. Contagious acute gastrointestinal infections. N Engl J Med 2004;351 (23): 2417-27. 
The famous enteric organism $S$ typhi is highly adapted to humans. This form of gastroenteritis is virtually always acquired by transmission from one person to another, implying an epidemiologic link in outbreaks [58].

Shigella has no reservoir in nature and spreads from person to person after direct contact or ingestion of contaminated food [58,61]. Outbreaks are commonly seen in day-care centers, spreading rapidly secondary to its highly contagious nature [58]. Shigella invades the small bowel, inducing inflammation and release of toxins [61].

Campylobacter is the most common bacterial cause of gastroenteritis. Transmission is similar to that of nontyphoidal salmonella. Most infections are traced to poultry, meat, dairy products, or contaminated water. The organism does not replicate well in food, limiting massive foodborne outbreaks [58]. Like Salmonella, Campylobacter passes through the small bowel and enters the terminal ileum, invading the submucosal and mucosal layers. The release of enterotoxin causes inflammation, impairs absorption, and elicits an immune response stimulating terminal ileal mesenteric lymph nodes to enlarge [61].

$E$ coli for the most part represents normal flora in the gastrointestinal tract. Five groups are pathogenic: enterotoxigenic (ETEC), enteropathogenic (EPEC), enteroinvasive (EIEC), enterohemorrhagic (EHEC), and enteroaggregation (EAggEC). Three of these bacteria commonly produce acute gastrointestinal infection [61]. ETEC produces enterotoxins that are similar to toxins produced by cholera. It will colonize the small intestine and release enterotoxin that binds to receptors on the enterocytes but does not damage them [61]. The toxins act on the glucose-mediated sodium pump and lead to secretion of water, with decreased absorption of water and electrolytes. It is the most common cause of "traveler's diarrhea" [57]. The most frequent serotype for EHEC is O157:H7 $[58,61]$. Its cytotoxin can cause damage to the kidneys and platelets, and cause hemolysis to red blood cells in a condition known as hemolytic uremic syndrome (HUS) [61]. HUS affects up to 13\% of young children infected. Transmission occurs from undercooked ground beef and person-to-person contact [58].

Salmonella and Campylobacter can produce a watery diarrhea in two thirds of cases and a bloody diarrhea in one-third of cases. Campylobacter and Yersinia can mimic appendicitis with right lower-quadrant pain secondary to production of mesenteric adenitis in the terminal ileum. Patients who have Shigella or EIEC can present with hemorrhagic colitis with fever and low-volume diarrhea. Seizures can occur in patients infected with Shigella. ETEC usually presents like a virus with large-volume watery stools [61]. EHEC presents with copious bloody diarrhea with mucus. Fever can be low grade or absent [57].

\section{Protozoal Gastroenteritis}

Common protozoan infection includes Cryptosporidium, Giardia, and Entamoeba histolytica [61]. Cryptosporidium is found in the feces of birds and cattle. It leaches through the soil into ground water and can be difficult to eradicate from drinking water. Person-to-person spread is well-documented. It can be particularly infectious in children, possibly illustrating better hygiene in adults [58]. 
Giardia infection is common with drinking fresh water from mountain streams or water supplies [61]. Outbreaks have occurred in child-care centers; it can also spread in swimming pools [58]. Symptomatic illness results from attachment to the mucosa of the duodenum and proximal jejunum.

$E$ histolytica's only reservoir is humans. It is transmitted from person to person by fecal-oral route or through contaminated food or water [61]. It can be spread in schools and day-care centers and among homosexual men [58]. The primary site of infection is in the colon, where it produces an inflammatory enteritis.

Cryptosporidium can present with frequent large-volume diarrhea, which can be clear and take on the appearance of "rice water diarrhea," as with cholera. Giardia may vary in volume and consistency, but is typically associated with flatulence, fever, vomiting, or cramps that may persist for over 14 days. $E$ histolytica can present with bloody stools without fever, but there is considerable variety in presentation [57,61].

The mainstay of treatment revolves around prevention with diligent hand washing, contact disinfection, avoiding contaminating water sources (ie, shared water bottles) and treatment of dehydration [57,61]. Secondary to the risk of dehydration and the high communicable rate of infection between teammates, it is not unreasonable to withhold an athlete from competition [59]. There is no specific treatment for viral enteritis. Most cases are short-lived, lasting only 1 or 2 days. $S$ enteritis should only be treated in immunocompromised individuals or those who have asplenia (secondary to predisposition to infection with encapsulated organisms) $[57,61]$. Antibiotics are not indicated in healthy individuals, because they do not shorten the illness but do prolong the carrier state [57]. Most cases of $E$ coli diarrhea are self-limited. Dysenteric illness should be treated with antibiotics [57]. Shigella manifesting with fever and dysentery should be treated because the antibiotic decreases fever, diarrhea, and excretion of the organism in the stool [57]. Campylobacter treatment is supportive and antibiotic treatment does not appear to improve the gastroenteritis. Early treatment is thought to be effective in eradicating the organism from the stool [57]. Giardia should be treated with antibiotics for comfort and to decrease transmission. Asymptomatic carriers and symptomatic patients who have entamoeba should be treated with antiparacytic medications. In immunocompetent hosts, Cryptosporidium is usually self-limited and does not require antiparacytic treatment [57]. Loperamide (Imodium) should never be used in dysenteric diarrhea [57] for fear of impairing the body's ability to clear the offending pathogen.

\section{TICK-BORNE DISEASES}

In the United States, tick-borne diseases are the most common vector-borne diseases. The mechanism of transmission is not well defined. Disease presents in many varieties, including Lyme disease, Rocky Mountain spotted fever (RSMF), ehrlichiosis, tularemia, tick-borne relapsing fever, Colorado tick fever, Babesiosis, and tick paralysis. For this article's purposes, the most com- 
mon North American varieties will be discussed, including; Lyme disease, Rocky Mountain spotted fever, and ehrlichiosis $[62,63]$.

\section{Lyme Disease}

Lyme disease is the leading vector-borne disease in the United States, and was first characterized in the 1970s. The causative agent is a spirochete, Borrelia (burgdorferi, afzelii, and garinii) first isolated in the early 1980s. Borrelia is transmitted by the Ixodes tick (deer tick, species specific to locale) [62-64]. The disease is endemic to the Northeast and North Central states and parts of the upper Midwest (New Hampshire, Connecticut, Rhode Island, New Jersey, Delaware, New York, Pennsylvania, Minnesota, and Wisconsin), and is spreading to new states [65]. Disease is most prevalent May through August, corresponding to peak human outdoor activity $[63,65]$.

Lyme disease is found in three stages. Stage 1, early localized stage, begins days to weeks following the tick bite. This stage may be characterized by the distinctive rash, erythema chronicum migrans, which occurs in $60 \%$ to $80 \%$ of cases. Mild systemic symptoms may accompany the rash, including fatigue, myalgias, arthralgias, headache, fever, and chills. Physical examination may reveal stiff neck and regional lymphadenopathy. If not recognized and treated, the skin lesion and symptoms will slowly resolve over 3 to 4 weeks $[62,64,66]$. The earliest manifestation of the second stage, early disseminated disease, can present as multiple secondary annular skin lesions within days to a few weeks after infection. These lesions can occur with the primary erythema chronicum migrans or not at all. If untreated they will resolve over days to weeks $[64,66]$. Many patients will not recall a tick bite or an erythema migrans type lesion. These individuals' first indication of disease may come as early stage 2, manifesting as neurologic symptoms in the form of cranial nerve palsies, motor or sensory peripheral neuropathies, and even lymphocytic meningitis. This is followed by weakness and absent reflexes. Untreated, the acute neurologic symptoms will typically resolve within weeks or months $[64,66]$. Approximately 6 months after infection, early disseminated disease may manifest as migratory and recurrent arthralgia, with periarticular pain or as frank arthritis of large joints (especially the knee) $[63,64,66]$. Cardiac involvement can present in varying degrees of atrioventricular block (first, second, or third). Unusually, cardiac symptoms can manifest in the form of myocarditis/pericarditis and congestive heart failure $[63,64,66]$. Often conduction defects are asymptomatic; any patient diagnosed with Lyme disease should have a screening electrocardiogram [66]. Stage 3, late Lyme disease, is characterized most commonly by chronic arthritis or neurologic system involvement $[63,64,66]$. They rarely occur concomitantly [66]. The arthritis is usually monoarticular, asymmetric, and confined to large joints (ie, knee). It may recur once or as multiple intermittent episodes over months to years $[63,64,66]$. Severity of the arthritis increases with age [66]. Most often there is no permanent joint damage and the process resolves over the course of several years; $[62,63,66]$; however, arthropathy or arthralgias may be persistent [66]. Late neurologic 
disease can manifest in the form of chronic encephalopathy with mild cognitive defects, sensory or motor neuropathies, and even leukoencephalopathies $[63,66]$.

The diagnosis of Lyme disease is based on recognition of characteristic findings in the history and physical, including exposure in an endemic area coupled with an antibody response to $B$ burgdorferi by enzyme-linked immunosorbent assay (ELISA) and western blotting. Serologic testing may not be sensitive in the first several weeks following infection. Usually antibody responses will become positive by 4 weeks after infection when IgG titers begin to rise. IgM titers may persist for years after treatment; therefore, IgM should only be interpreted as evidence for recent infection with the appropriate clinical characteristics $[64,66]$.

Treatment with oral doxycycline for 14 to 21 days is effective in early disease for persons 8 years old or more; treatment with amoxicillin is effective in early disease in pregnant women or children younger than 8 . For patients allergic to either of these medications, cefuroxime is the first alternative, followed by erythromycin. Doxycycline carries the advantage of eradication of coinfection with ehrlichiosis. Neurologic disease should be treated with a 2- to 4-week course of parenteral antibiotics in the form of ceftriaxone or cefotaxime. Penicillin $\mathrm{G}$ may be a satisfactory alternative. Oral doxycycline is effective for the treatment of Lyme-associated facial palsy [64,66]; however, diffuse neurologic disease may be present, and is better treated with parenteral antibiotics.[64] Lyme carditis, manifesting with atrioventricular (AV) node block (PR interval $>0.3$ second) should be treated with intravenous antibiotics and cardiac monitoring. Usually, pacemaker placement is not necessary. For late manifestations of Lyme arthritis, either oral doxycycline or intravenous ceftriaxone are effective [64].

\section{Rocky Mountain Spotted Fever}

RMSF was the first tick-borne illness described in the Northwest United States, in the late 1800 s $[62,63,67,68]$. It is caused by the organism Rickettsia rickettsii and transmitted by two tick species in the United States: Dermacentor viriabilis (dog tick) in Eastern states and Dermacentor andersoni (wood tick) in Western states $[63,67]$. In the United States, most infection occurs in the South Atlantic coastal states and the Midwestern states, with the greatest numbers of cases reported in North Carolina, Oklahoma, Tennessee, Arkansas, South Carolina, Maryland, and Virginia. There is a clear spring-to-summer distribution, with most cases occurring from April to September $[67,68]$. The incidence is highest among children, with fatality rates being highest amongst individuals older than 40 and in males $[63,68]$. Risk factors include exposure to dogs, residence in a wooded area, and male sex [63]. RMSF remains the most lethal of all the tick-borne disease in the United States, largely because of difficulty in early diagnosis $[67,68]$. Infection results in involvement of endothelial and smooth muscle cells of blood vessels of the skin and internal organs, which causes a vasculitis $[62,68]$. 
The incubation for RMSF averages about 7 days after the infecting tick bite $[62,68]$. RMSF can present with the triad of rash, fever, and headache; however, the triad in combination with history of tick exposure is reported to occur in only $60 \%$ to $70 \%$ of confirmed cases $[63,68]$. Retrospective studies have indicated that more than half of all patients in the early phases of RMSF were not recognized to be infected. Presentation within 3 days of onset of symptoms is associated with a longer delay in diagnosis than in patients who present after 3 days onset of symptoms [68]. Within 2 to 14 days following a tick bite, the illness will abruptly begin, with a combination of nonspecific symptoms including fever (usually $100 \%$ of cases), malaise, severe frontal headache, myalgias, and vomiting with or without abdominal pain $[62,63,68]$. Often the condition is misdiagnosed as gastroenteritis or an acute abdomen $[63,67]$. Occasionally the patient may develop hepatosplenomegaly, diarrhea, conjunctivitis, lymphadenopathy, mental confusion, meningismus, encephalitis, respiratory failure, renal dysfunction, coagulopathy, cardiac disturbances in the form of myocarditis or cardiac arrhythmia, and gastrointestinal bleeding during the course of the illness [63]. The rash will typically begin within the first week of infection in the form of blanching 1 to $4 \mathrm{~mm}$ macules that later become petechiae. Occasionally, RMSF may be spotless or almost spotless [67,68]. Classically, the rash forms on the wrists and ankles and spreads centrally $[62,63,68]$; however, this textbook description is rarely observed. In many cases, the rash begins as a maculopapular exanthema, which then evolves into a petechial rash [68].

Initial laboratory testing reveals normal or a slightly depressed white blood cell count, thrombocytopenia, elevated liver enzymes, and hyponatremia. Diagnosis is based on clinical signs and symptoms, physical examination, and nonspecific laboratory examination $[62,68]$. Antibiotic therapy is never withheld while waiting for return of diagnostic tests [68]. The best and most widely used serologic confirmation is with indirect fluorescent antibody (IFA) testing for IgM and IgG antibodies to $R$ rickettsii, which appear 10 to 14 days after infection.

The mortality rate in RMSF is extremely high, reaching 25\% in untreated cases and $5 \%$ in treated cases $[62,63]$. Because the diagnosis is usually suspected on purely clinical grounds, initial therapy is usually empiric. Many patients in the early stages of disease can be treated as outpatients with tetracyclines (doxycycline being the agent of choice) for 7 to 10 days. More severe illness should be treated with intravenous (IV) medication.

\section{Ehrlichiosis}

Ehrlichiosis was first identified in humans in 1987 when the organism was found in human monocytes, and the causative agent was named Ehrlichia chaffeenis (genus Rickettsiaceae). This disease process was termed human monocytotrophic ehrlichiosis (HME). Later, in a similar illness, Ehrlichia were found in polymorphonucleocytes. This disease was named human granulocytotropic ehrlichiosis (HGE), caused by Ehrlichia phagocytophilia or Ehrlichia ewingï. 
HME occurs mostly in the South-Central region, the Southeastern and Middle Atlantic states, and California. HGE occurs mainly in the southern New England states, the Middle Atlantic states, the upper Midwest states and Northern California. Vectors in North America for HME include Amblyomma americanum (lone star tick) and Dermacentor variabilis. Vectors for HGE include Ixodes scapularis in the eastern and midwestern United States and Ixodes pacificus in California. Most cases of HME and HGE occur between April and September [69].

The clinical presentation for HME ranges from mild viral-like illness to moderate disease to fatal disease. The onset of disease is abrupt, occurring 7 to 10 days after tick bite and presenting with nonspecific symptoms such as fever, severe headache, malaise, chills, and rash. The rash can be macular, papular, maculopapular, or reticular, involving the trunk and sparing the hands and feet (not associated with the site of the tick bite) [69,70]. Other signs and symptoms include myalgias, arthralgias, lymphadenopathy, anorexia, abdominal pain, diarrhea, nausea, and vomiting. More severe complications involve the respiratory, central nervous, gastrointestinal (GI), cardiac, hematologic, and renal systems. HGE appears to have a less severe spectrum, with lower frequency of life-threatening manifestations [69].

Diagnosis is based on clinical history, including exposure to ticks, signs and symptoms, and abnormal routine laboratory tests. As in the other rickettsial diseases, there are nonspecific laboratory findings including leukopenia, thrombocytopenia, and anemia. Hepatic transaminases can be elevated in both diseases, as can nonspecific inflammatory markers including erythrocyte sedimentation rate (ESR) and C-reactive protein (GRP) [69,70]. Indirect immunofluoresence is the gold standard for diagnosis. PCR is a valuable test during the acute phase of disease, with sensitivity reaching $67 \%$ to $87 \%$ and specificity reaching close to $100 \%$.

Treatment is based on clinical suspicion and should not be delayed for confirmation. Both ehrlichioses respond well to tetracyclines. Again, doxycycline is the antibiotic of choice. Oral versus parenteral treatment is based on severity of presentation. Response is usually seen within 24 to 48 hours of treatment. The prognosis is worse in patients of advanced age or who have chronic disease $[69,70]$.

Prevention of tick-borne diseases revolves around prevention of tick bites. If endemic areas and predisposing environments (wooded areas) cannot be avoided, protective clothing (including long pants cinched at the ankles or tucked into boots, long-sleeved shirts, and hats) should be worn. Repellants containing diethyltoluamide (DEET) should be worn on clothes and exposed surfaces to repel ticks. All body parts should be inspected closely when traveling in tick-infested areas. If a tick is encountered, rapid removal lessens the chance for disease transmission. A tick should be lifted cleanly from the skin surface with a blunt forceps or tweezers by applying steady pressure and taking care not to crush or squeeze the body. Antibiotic prophylaxis is generally not indicated for asymptomatic tick bites [70]. 


\section{URINARY TRACT INFECTIONS}

Urinary tract infection (UTI) is one of the most common medical conditions in sexually active adolescents and young adult women [71]. The incidence in adolescent and college women varies with risk factors. Sexual activity increases the risk [71-74]. Frequency of sexual activity and use of a diaphragm and spermicide increase relative risk of asymptomatic and symptomatic UTI [71-74]. There is a strong independent association and dose-response relationship between sexual intercourse and risk of symptomatic UTI [73]. Recent sexual intercourse is also significantly associated with asymptomatic bacteriuria [74]. Exposure to spermicide can increase the risk of vaginal colonization and bacteriuria with $E$ coli [72,73] or $S$ saprophyticus [72], whether exposure occurs with the use of a diaphragm or spermicide-coated condom; however, there is an increased risk of bacteriuria with use of a spermicide and diaphragm together [73]. Previous episodes of cystitis are also related to an increased incidence of symptomatic UTI $[72,73]$.

UTI in men less than 50 years old is rare. Usually infections in young men are thought to be related to an underlying urologic abnormality and are labeled as complicated. Risk factors associated with men (age 15-50) and acute cystitis include homosexuality (exposure to $E$ coli through anal intercourse), intercourse with an infected partner secondary to vaginal colonization, and lack of circumcision (enhanced colonization of the glans and prepuce by $E$ coli) $[75,76]$.

UTI is classified as upper tract, lower tract, or both, based on symptoms. Lower tract infection, commonly referred to as cystitis, can present with dysuria, suprapubic pain or pressure, urinary frequency, urgency, dribbling, or hematuria $[71,72,77]$. Symptoms associated with vaginitis/cervicitis include vaginal discharge, odor, pruritis, irritation, or dyspareunia, and decrease the likelihood of cystitis [72,77]. The combination of dysuria and frequency of urination, in the absence of vaginal discharge, has been found to have a posttest probability of $96 \%$ in predicting cystitis in a systematic review [77]. Fever $\left(>38^{\circ} \mathrm{C}\right)$, flank pain, costovertebral angle tenderness, nausea, or vomiting usually indicates upper-tract involvement in otherwise healthy individuals [71,72].

Urinalysis in the presence of pyuria has a sensitivity of $95 \%$, with a low specificity of $71 \%$ in the diagnosis of infection. The presence of visible bacteria on microscopic examination is less sensitive $(40 \%-70 \%)$ but more specific $(85 \%-95 \%)$. Urinary dipstick method of diagnosis is frequently used in the diagnosis of UTI because it is cheap, fast, and convenient. Dipstick sensitivity and specificity rise to $75 \%$ and $82 \%$, respectively, when nitrite or leukocyte esterase are present [72]. Based on available data, it appears reasonable to empirically treat for UTI when the probability of infection is high, and reserve the above diagnostic tests for when the diagnosis is called into question [77]. A negative test result on dipstick or urinalysis, with a high pretest probability, cannot rule out infection. In this case, it is appropriate to obtain urine culture $[72,77]$. Culture is also warranted when unusual organisms are suspected or when symptoms do not resolve within 2 to 4 weeks after treatment [72,77]. 
The most common bacteriologic agents causing uncomplicated infection include $E$ coli (75\%-90\% of cases) and Staphylococcus saprophyticus (5\%-15\% of cases). Enterococci and non- $E$ coli aerobic gram-negative rods such as Klebsiella and Proteus make up the remaining 5\% to $10 \%$ of cases. These agents are felt to be the same causes in uncomplicated pyelonephritis [78].

When treating cystitis, it is prudent to pay close attention to your community's bacterial resistance and susceptibility patterns. Before antibiotic selection, take into consideration recent antimicrobial use, recent hospitalization, and history of recurrent UTI infection. If the patient has not used trimethoprimsulfamethoxazole (TMP-SMX) in the last 6 months and your community resistance patterns reveal less than $10 \%$ to $20 \%$ resistance to TMP-SMX, then double-strength TMP-SMX twice daily for 3 days is the drug of choice for uncomplicated cystitis [78]. In this scenario, it is estimated that TMP-SMX achieves bacteriologic cure within 7 days in 94\% of women [72]. If the patient does not meet the above criteria or is allergic to TMP-SMX, a fluoroquinolone (3 days), nitrofurantonin (7 days), or fosfomycin (single-dose) should be used. For acute uncomplicated pyelonephritis (no signs of systemic toxicity, able to self hydrate, and take oral medications) [72], fluoroquinolones are the treatment of choice. Repeated UTI in young women and adolescents should raise concern for possible STD [71].

\section{EPIDIDYMITIS/ORCHITIS AND PROSTATITIS}

\section{Epididymitis/Orchitis}

Nontraumatic scrotal pain encompasses a large array of differential diagnoses, including testicular torsion, inguinal hernia, idiopathic scrotal edema, hydrocele/ varicocele, renal colic, idiopathic testicular infarction, testicular tumor, leukemia, scrotal abscess, epididymitis, and orchitis. Although all of these diagnoses should be considered in the athlete presenting with an irritated or painful scrotum [79], this section deals with the most common infectious causes, including epididymitis and orchitis. Epididymitis is the most common cause of acute scrotum in adolescent boys and young men [80,81].

A complete history and physical can often provide insight into the possible etiology of a painful scrotum. When considering infectious etiologies, the age of the patient is often helpful. Sexually transmitted pathogens such Neisseria gonorrhea and Chlamydia trachomatis are common in men younger than 35 . This is the most common cause of epididymitis or epididymo-orchitis in adolescent boys and young men [79-81]. Atypical sexually transmitted pathogens, such as Ureaplasma urealyticum, must be considered if no Gonococcal organisms are identified [80]. Uropathogens such as E coli and Proteus mirabilis are frequent causes in prepubescent boys and men over the age of 35 years [79-81]. Mumps is the most common cause of orchitis without associated epididymitis, and usually presents bilaterally 4 to 6 days following a mumps parotitis $[80,81]$.

Acute epididymitis/epididymo-orchitis can be difficult to distinguish from testicular torsion. Ultrasound is useful to rule out testicular torsion if the 
diagnosis is in question based on history and physical examination [82]. If the patient's presentation reveals a short duration of pain with a correlating history and physical examination for torsion, the patient may be more appropriate for surgical exploration rather than delaying treatment for ultrasound examination. Any young male presenting with acute scrotal pain deserves prompt evaluation for testicular torsion. Epididymitis usually presents insidiously with increasing, dull, unilateral scrotal pain $[79,82]$. Urinary tract symptoms including dysuria, frequency, and urgency may be present [82]. Once fully developed, the pain can be excruciating [79] and may extend up the spermatic cord and into the lower abdomen $[79,82]$. Should infection spread into the testes, swelling and a reactive hydrocele can develop $[79,82]$. The physical examination can reveal an erythematous, swollen, and tender epididymis or scrotum, depending on the spread of infection and time to presentation. The patient may be febrile $[79,82]$. Urethral milking may reveal urethral discharge [79]. Patients often report relief of pain with elevation of the testicle, known as Prehn's sign. The cremasteric reflex is normally intact. None of these signs are specific for epididymitis, and their presence should warrant further investigation [82]. Urinalysis, urine culture, and urethral culture or urine DNA amplification for gonorrhea and chlamydia should be sent for laboratory evaluation. Urinalysis may reveal pyuria with bacteria present $[79,82]$. White blood count may reveal a peripheral leukocytosis with a left shift [79].

Treatment of epididymitis involves empiric treatment for suspected etiologies. In patients who are prepubescent or elderly, the antibiotic should cover urinary pathogens (prostatic pathogens in men $>35$ years old) and be adjusted based on urinary culture $[79,82]$. These patients warrant urinary tract imaging and studies to assess for structural abnormalities. This also holds true for an adolescent or young man diagnosed with a urinary pathogen as the cause for epididymitis [82]. Patients suspected of having a sexually transmitted cause should be treated with recommended protocols for $\mathcal{N}$ gonorrhea and $C$ trachomatis with ceftriaxone $250 \mathrm{mg}$ intramuscularly and doxycycline $100 \mathrm{mg}$, twice daily for 10 days. For men over the age of 35 years, treatment consists of an oral fluoroquinolone (ofloxacin or levofloxacin) for 10 days [83]. If the epididymitis is severe, parental antibiotics can be used. All sexual partners should also be treated. Symptomatic treatment revolves around inflammatory reduction with scrotal elevation, bed rest, anti-inflammatory agents, and ice. Narcotic pain control may also be needed [79].

\section{Prostatitis}

Acute prostatitis is an uncommon condition seen in most training rooms; however, prostatitis syndromes tend to occur in young and middle-aged men 18 to 50 years old and men older than 50 (most commonly diagnosed in men 36 to 65 years old) [84]. The symptoms include pain (perineum, lower abdomen, lower back, testicles, penis, rectum, and with ejaculation or urination), bladder irritation, bladder outlet obstruction, blood in semen, and occasionally impotence. It is estimated by the National Ambulatory Care Survey that 
20 office visits per 1000 men per year were for symptoms compatible with prostatitis [85].

The most common pathogens include Enterobacteriacae organisms, E coli, Klebsiella, Pseudomonas aeruginosa, and Proteus species. Antibiotic therapy should be directed at these pathogens and achieve adequate prostatic tissue penetration. Frequently, doxycycline, TMP-SMX, and fluoroquinolones are the antibiotics of choice [85].

\section{SEXUALLY TRANSMITTED DISEASES}

A multicenter, cross-sectional study looking at lifestyle and health risks of collegiate athletes found that college athletes appear to be at higher risk than their nonathletic peers for certain maladaptive lifestyle behaviors, including unsafe sex, greater number of sexual partners, and less contraceptive use [4]. Perhaps these behaviors are what have led to an increase in prevalence seen in STDs in adolescents and young adults. Comprehensive guidelines for diagnosing and treating STDs can be found in the Center for Disease Control (CDC) 2002 Sexually Transmitted Diseases Treatment Guidelines report (http://www. cdc.gov/std/treatment/rr5106.pdf) [83].

This section highlights a growing problem seen in the adolescent and young adult population in the United States, and discusses recommendations for screening, diagnostic tests, and guidelines for participation in athletes infected with a blood-borne pathogen. Recent research has indicated that the prevalence of asymptomatic chlamydia in young adults age 18 to 26 is high. This increased prevalence reveals significant racial and ethnic disparities in both chlamydial and gonococcal infections [86]. The highest rates of chlamydia have been reported in the grouyp 15 to 24 years old. HIV/AIDS infection is the second leading cause of morbidity in the world, and is contracted most commonly by individuals aged 15 to 25. Human papillomavirus (HPV) is the most widespread sexually transmitted disease in the world. The CDC estimates that 50\% to $75 \%$ of sexually active men and women acquire HPV at some point in their lives. It has also been estimated that $35 \%$ of teens and young adults in various Western countries have acquired HPV. Approximately $20 \%$ of the US adult population is infected with $\mathrm{HSV}$, which is a 30\% increase in the last 25 years [87]. The staggering reality associated with these statistics is that they belong to the very population that sports medicine specialists spend the majority of their time treating. STDs pose significant morbidity in regards to long-term sequelae of reproductive health in the form of cervical intraepithelial neoplasia, tubal infertility, ectopic pregnancy, and continued painful genital lesions, which take significant tolls on physical and psychosexual health. In its severe form, STD can even impact mortality through death [87].

The CDC recommends the screening of all sexually active women younger than 24 years of age, whether symptomatic or asymptomatic. Women older than 24 years of age should be screened if they are at risk for chlamydial infection (ie, new sexual partner or history of multiple partners) $[83,88]$. Screening in the young adult population makes sense. Studies looking at screening 
for STDs during preparticipation sports examination found a prevalence in females for Chlamydia and Gonorrhea of 6.5\% and 2.0\%, respectively; and 2.8\% and $0.7 \%$ in males, respectively. Of the individuals that were infected, $93.1 \%$ had no symptoms [89]. Studies in adolescents have documented short periods of time (4.7-7.6 months) until reinfection occurs, suggesting that sexually active adolescents should be screened every 6 months [90].

The CDC recommends immunization of all children and adolescents for hepatitis B. Hepatitis A vaccination is recommended for homosexual men and illegal substance abusers [83]. HPV Type 16 vaccination is being studied and offers promise for prevention of HPV type 16 infection and related cervical cancer [91].

Infection with blood-borne pathogens such as HIV or bepatitis B virus (HBV) offers challenges for determining eligibility for competition. Based on available data, there has never been a documented transmission of HIV during athletic competition. Therefore, there are no recommendations for holding an HIV-infected athlete out of competition if the individual is in otherwise good health. The HBV-infected athlete represents a more distinct transmission risk, with a higher chance of blood exposure in contact sports. Therefore, the National Collegiate Athletic Association (NCAA) recommends removal of athletes who have acute $\mathrm{HBV}$ infection until loss of infectivity is known. Athletes who have chronic HBV infection should be withheld from contact sport indefinitely [92]. Obviously, when dealing with any blood exposure, universal precautions should be followed. Any contaminated surface should be decontaminated with approved disinfectants.

In light of the increased prevalence of STDs, it is important for health care providers to provide greater emphasis on prevention and management of STDs. This is especially true for sports medicine specialists, in light of their primary patient population. The goal should be to promote a program that is comprehensive in its screening, recognition, and management of STDs; including the recognition and education of athletes practicing high-risk behaviors.

\section{SUMMARY}

Athletes will experience the affects of common infectious diseases. The training room offers the sports medicine physician an environment that is safe and convenient to the athlete; often providing athletes their only form of medical care. If sports medicine clinicians are well-versed in the presentation, diagnosis, and treatment of common infectious diseases; they will be able to have a significant impact in the care of the athlete. Prompt care in the training room setting will decrease hindrances to the athlete's participation, performance, and long-term well-being. The training room also provides a unique setting for prevention, screening, and education concerning high-risk behavior in athletes.

\section{References}

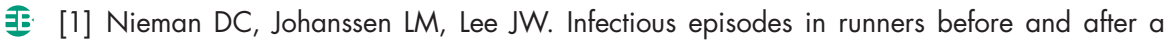
roadrace. J Sports Med Phys Fitness 1989;29:289-96.

[2] Schouten WJ, Verschuur R, Kemper HCG. Physical activity and upper respiratory tract 
infections in a normal population of young men and women: the Amsterdam growth and health study. Int J Sports Med 1988;9:451-5.

[3] Strauss RH, Lanese RR, Leizman DJ. Illness and absence among wrestlers, swimmers, and gymnasts at a large university. Am J Sports Med 1988;16(6):653-5.

[4] Nattiv A, Puffer JC, Green GA. Lifestyles and health risks of collegiate athletes: a multicenter study. Clin J Sport Med 1997;7:262-72.

[5] Hanley DF. Medical care of the US Olympic team. JAMA 1976;236:147-8.

[6] Ilback NG, Fohlman J, Friman G. Exercise in Coxsackie B3 myocarditis: effects on heart lymphocyte subpopulations and the inflammatory reaction. Am Heart J 1989; 117:1298-302.

[7] Maron BJ, Epstein SE, Roberts WC. Causes of sudden death in the competitive athlete. J Am Coll Cardiol 1986;7:204-14.

[8] Sevier TM. Infectious disease in athletes. Sports Med 1994;78(2):389-412.

[9] Daniels WL, Vogel JA, Sharp DS, et al. Effects of virus infection on physical performance in man. Mil Med 1985; 150(1):8-14.

[10] Weidner TG, Cranston T, Schurr T, et al. The effect of exercise training on the severity and duration of viral upper respiratory illness. Med Sci Sports Exerc 1998;30(1 1):1578-83.

[11] Weidner TG, Anderson BN, Kaminsky LA, et al. Effect of a rhinovirus-caused upper respiratory illness on pulmonary function test and exercise responses. Med Sci Sports Exerc 1997;29:604-9.

[12] Metz JP. Upper respiratory tract infections: who plays, who sits? Curr Sports Med Rep 2003;2:84-90.

[13] Eichner ER. Infection, immunity, and exercise: what to tell patients. Phys Sportsmed 1993; 21:125-35.

[14] Wilckens JH, Glorioso JE. Risk assessment and management of nonorthopaedic conditions; viral disease. In: Delee JC, Drez D, Miller MD, editors. Orthopaedic sports medicine principles and practice. 2nd edition. Philadelphia: WB Saunders; 2002. p. 251-63.

[15] Bisno AL. Acute pharyngitis. N Engl J Med 2001;344(3):205-11.

[16] Hickner JM, Bartlett JG, Besser RE, et al. Principles of appropriate antibiotic use for acute rhinosinusitis in adults: background. Ann Intern Med 2001;134:498-505.

[17] Scheid DC, Hamm RM. Acute bacterial rhinosinusitis in adults. Part I. Evaluation. Am Fam Physician 2004;70(1):1685-92.

[18] Gwaltney Jr JM, Scheld WM, Sande MA, et al. The microbial etiology and antimicrobial therapy of adults with acute community-acquired sinusitis: a fifteen-year experience at the University of Virginia and review of other selected studies. J Allergy Clin Immunol 1992; 90(457):457-61.

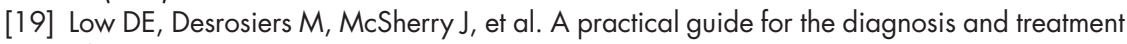
of acute sinusitis. CMAJ 1997;156(Suppl 6):S1-14.

[20] Lanza DC, Kennedy DW. Adult rhinosinusitis defined. Otolaryngol Head Neck Surg 1997;1 17:S1-7.

[21] Deitmer T, Scheffler R. Nasal physiology in swimmers and swimmers sinusitis. Acta Otolaryngol 1990;110(3-4):286-91.

[22] Schelkun PH. Swimmer's ear: Getting patients back in the water. Phys Sportsmed $1991 ; 19(7): 85-90$.

[23] Nichols AW. Nonorthopaedic problems in the aquatic athlete. Clin Sports Med 1999; 18(2):395-411.

[24] Russell JD, Donnelly M, McShane DP, et al. What causes acute otitis externa? J Laryngol Otol 1993; 107:898-901.

[25] Morrow GL, Abbott RL. Conjunctivitis. Am Fam Physician 1998;57(4):735-46.

[26] Rietveld RP, van Weert HC, ter Riet G. Diagnostic impact of signs and symptoms in acute infectious conjunctivitis: systematic literature search. BM 2003;327(7418):789.

[27] Leibowitz HM. The red eye. N Engl J Med 2000;343(5):345-51.

[28] Papesch $M$, Watkins R. Epstein-Barr virus infectious mononucleosis. Clin Otolaryngol $2001 ; 26(1): 3-8$. 
[29] Maki DG, Reich RM. Infectious mononucleosis in the athlete. Diagnosis, complications, and management. Am J Sports Med 1982;10(3):162-73.

[30] Evans AS, Niederman JC. Epstein-Barr virus. In: Evans AS, editor. Viral infections of humans: epidemiology and control. New York: Plenum Publishing; 1989. p. 253-81.

[31] MacKnight JM. Infectious mononucleosis: ensuring a safe return to sport. Phys Sportsmed 2002;30(1):27-8.

[32] Dommerby $H$, Stangerup SE, Stangerup $M$, et al. Hepatosplenomegaly in infectious mononucleosis, assessed by ultrasonic scanning. J Laryngol Otol 1986;100(5):573-9.

[33] Hoagland RJ. Infectious mononucleosis. Prim Care 1975;2:295-307.

[34] Farley DR, Zietlow SP, Bannon MP, et al. Spontaneous rupture of the spleen due to infectious mononucleosis. Mayo Clin Proc 1992;67:846-53.

[35] Frelinger DP. The ruptured spleen in college athletes: a preliminary report. J Am Coll Health Assoc 1978;26:217.

[36] Maki DG, Reich RM. Infectious mononucleosis in the athlete: diagnosis, complications, and management. Am J Sports Med 1982;10(3):162-73.

[37] Tamayo SG, Rickman LS, Mathews WC, et al. Examiner dependence on physical diagnostic tests for the detection of splenomegaly: a prospective study with multiple observers. J Gen Intern Med 1993;8(2):69-75.

[38] Hosey RG, Quarles JD, Kriss VM, et al. Spleen size in athletes-a comparison of BMI, gender, race, and past history of mononucleosis. Med Sci Sports Exerc 2004;36:5;S3 12.

[39] Eichner ER. Infectious mononucleosis. Phys Sportsmed 1996;24:49-54.

[40] Rutkow IM. Rupture of the spleen in infectious mononucleosis: a critical review. Arch Surg $1978 ; 113: 718-20$.

[41] Matheson GO, Boyajian-O'Neill LA, Cardone D, et al. In: Wappes JR, editor. Preparticipation physical evaluation monograph. 3rd edition. Minneapolis (MN): McGraw Hill; 2004. p. 1-98.

[42] Kastenbauer S, Pfister HW. Pneumococcal meningitis in adults, spectrum of complications and prognostic factors in a series of 87 cases. Brain 2003;126:1015-25.

[43] Moore M, Baron RC, et al. Aseptic meningitis and high school football players, 1978 and 1980. JAMA 1983;249(15):2039-42.

[44] Centers for Disease Control. Aseptic meningitis in a high school football team, Ohio. MMWR Morb Mortal Wkly Rep 1981;29:631-7.

[45] Baron RC, Hatch MH, Kleeman K, et al. Aseptic meningitis among members of a high school football team. JAMA 1982;248(14):1724-7.

[46] Thomas JC, Chun L. Aseptic meningitis in football players. J Sch Health 1990;60:11.

[47] Alexander JP, Chapman LE, Pallansch MA, et al. Coxsackeivirus $B_{2}$ infection and aseptic meningitis; a focal outbreak among members of a high school football team. J Infect Dis 1993; 167:1201-5.

[48] Goodman RA, Thacker SB, Solomon SL, et al. Infectious diseases in competitive sports. JAMA 1994; 16(11):862-7.

[49] Johnson RP. Aseptic meningitis. Up To Date Online 2005V12.3 Available at www. uptodate.com. Accessed January 2, 2005.

[50] Moeller JL. Aseptic meningitis: a seasonal concern. Phys Sportsmed 1997;25(7):34-42.

[51] Rajnik M, Ottolini MG. Serious infections of the central nervous system: encephalitis, meningitis, and brain abscess. Adolesc Med 2000;1 1 (2):401-24.

[52] Coyle PK. Overview of acute and chronic meningitis. Neurol Clin 1999;17(4):691-709.

[53] Sigurdardottir B, Biornsson OM, Jonsdottir KE, et al. Diagnosis of bacterial meningitis in adults: a 20 year review. Arch Intern Med 1997;157:425-30.

[54] Nelson S, Sealy DP. The aseptic meningitis syndrome. Am Fam Physician 1993;48(5): 809-15.

[55] Advisory Committee on Immunization Practices (ACIP). Prevention and control of meningococcal disease. MMWR Morb Mortal Wkyl Rep 2000;49:1.

[56] Baker CJ. Recommendations pending for meningococcal vaccine. American Academy of Pediatrics News 2005;26(1):1,12. 
[57] Adachi AA, Backer HD, DuPont HL. Infectious diarrhea from wilderness and foreign travel. In: Auerbach PS, editor. Wilderness medicine. 4th edition. St. Louis (MO): Mosby; 2001. p. 1237-70.

[58] Musher DM, Musher BL. Contagious acute gastrointestinal infections. N Engl J Med 2004;351 (23):2417-27.

[59] Buescher ES. Infections associated with pediatric sport participation. Pediatr Clin North Am 2002;49:743-51.

[60] Becker KM, Moe CL, Southwick KL, et al. Transmission of Norwalk virus during a football game. N Engl J Med 2000;343:1223-7.

[61] Marsh WW. Infectious diseases of the gastrointestinal tract. Adolesc Med 2000;11(2): 263-78.

[62] Gayle A, Ringdahl E. Tick-borne diseases. Am Fam Physician 2001;64(3):461-6.

[63] Spach DH, Liles WC, Campbell GL, et al. Tick-borne diseases in the United States. N Engl J Med 1993;329(13):936-47.

[64] Steere AC. Lyme disease. N Engl J Med 2002;345(2):115-25.

[65] Centers for Disease Control. Lyme disease-United States, 2001-2002. MMWR Morb Mortal Wkly Rep 2004;53:365-9.

[66] Sood SK. Lyme disease. Pediatr Infect Dis J 1999;18(10):913-25.

[67] Masters EJ, Olson GS, Weiner SJ, et al. Rocky Mountain spotted fever. Arch Intern Med 2003; 163:769-74.

[68] Sexton DJ, Kaye KS. Rocky Mountain spotted fever. Med Clin North Am 2002;86(2): $351-60$.

[69] Olano JP, Walker DH. Human ehrlichioses. Med Clin North Am 2002;86(2):375-92.

[70] Gentile DA, Lang JE. Tick-borne diseases. In: Auerbach PS, editor. Wilderness medicine. 4th edition. St. Louis (MO): Mosby; 2001. p. 769-806.

[71] Weir M, Brien S. Adolescent urinary tract infections. Adolesc Med 2000;1 1 (2):293-312.

[72] Fihn SD. Acute uncomplicated urinary tract infection in women. N Engl J Med 2003; 349(3):259-66.

[73] Hooten TM, Scholes D, Hughes JP, et al. A prospective study of risk factors for symptomatic urinary tract infections in young women. N Engl J Med 1996;335(7):468-74.

[74] Hooten TM, Scholes $D$, Stapleton $A E$, et al. A prospective study of asymptomatic bacteriuria in sexually active young women. N Engl J Med 2000;343(14):992-7.

[75] Stamm WE, Hooton TM. Management of urinary tract infections in adults. N Engl J Med 1993;329(18):1328-34.

[76] Hooton TM, Stamm WE. Diagnosis and treatment of uncomplicated urinary tract infection. Infect Dis Clin North Am 1997;1 1(3):551-81.

[77] Bent S, Nallamothu BK, Simel DL, et al. Does this woman have an acute uncomplicated urinary tract infection? JAMA 2002;287(20):2701-10.

[78] Gupta K, Hooton T, Stamm WE. Increasing antimicrobial resistance and the management of uncomplicated community-acquired urinary tract infections. Ann Intern Med 2001; 135(1):41-50.

[79] Marcozzi D, Suner S. The nontrauamtic acute scrotum. Emerg Med Clin North Am 2001; 19(3):547-67.

[80] O'Brien WM, Lynch JH. The acute scrotum. Am Fam Physician 1988;37(3):239-47.

[81] Dogra V, Bhatt S. Acute painful scrotum. Radiol Clin N Am 2004;42:349-63.

[82] Kass EJ, Lundak B. The acute scrotum. Pediatr Clin North Am 1997;44(5):1251-66.

[83] Centers for Disease Control and Prevention. 2002 sexually transmitted diseases treatment guidelines. MMWR Morb Mortal Weekly Rep 2002;51:1-78.

[84] Collins MM, Stafford RS, O'Leary MP, et al. How common is prostatitis? A national survey of physician visits. J Urol 1998;159(4):1224-8.

[85] Schaeffer A. Etiology and management of chronic pelvic pain syndrome in men. Urology 2004;63(Suppl 3A):75-84.

[86] Miller WC, Ford CA, Morris M, et al. Prevalence of chlamydial and gonococcal infections among young adults in the United States. JAMA 2004;291(18):2229-36. 
[87] Genuis SJ, Genuis SK. Managing the sexually transmitted disease pandemic: a time for reevaluation. Am J Obstet Gynecol 2004; 191(4):1103-12.

[88] Miller KE, Ruiz DE, Graves JC. Update on the prevention and treatment of sexually transmitted diseases. Am Fam Phsycian 2003;67(9):379-86.

[89] Nsuami $M$, Elie $M$, Brooks BN, et al. Screening for sexually transmitted diseases during preparticipation sports examination of high school adolescents. J Adolesc Health 2003; 32(5):336-9.

[90] Spigarelli MG, Biro FM. Sexually transmitted disease testing: evaluation of diagnostic tests and methods. Adolesc Med 2004;15:287-99.

[91] Koutsky LA, Ault KA, Wheeler CM, et al. Human papillomavirus type 16 vaccine reduced theincidence of both HPV-16 infection and HPV-related cervical intraepithelial neoplasia. N Engl J Med 2002;347:1645-51.

[92] NCAA guideline 2h; blood-borne pathogens and intercollegiate athletics. April 1998, revised August 2000. In: Schluep C, editor. 2003-2004 NCAA sports medicine handbook. p. 36-40. 